\author{
Military Technical College \\ Kobry El-Kobbah, \\ Cairo, Egypt.
}

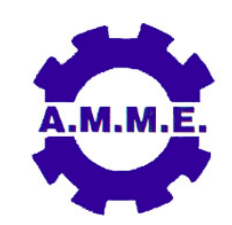

\title{
SURFACE GENERATION IN ULTRA-PRECISION TURNING CONSIDERING PROCESS UNCERTAINTY: MODELING AND EXPERIMENTAL VALIDATION
}

\author{
$17^{\text {th }}$ International Conference \\ on Applied Mechanics and \\ Mechanical Engineering.
}

\author{
S. Elsanabary ${ }^{1}$, A. Elkaseer ${ }^{2}$, S. Abd-Rabbo ${ }^{3}$, M. AbdElsalam ${ }^{4}$ and S. Abdou ${ }^{5}$
}

\begin{abstract}
This paper presents the development and experimental validation of a modeling approach that was proposed to predict the surface generation process during ultraprecision turning. In particular, in addition to the kinematic paramters, the proposed model takes into consideration the effects of the minimum chip thickness and elastic recovery along side their associated uncertainity attributable to the blend nature of the multi-phase materials. The model amis to eliminate the contribution of the uncertainty errors due to the stochastic behavior of the phases presents within the material microstructe. Thus, it allows predicting the achievable surface roughness more preciously under different cutting conditions. The developed model was experimentally validated by machining dual-phase material, Brass 6040, under a range of processing parameters. The roughness of the generated surface was measured and compared with those estimated by the model under similar conditions. Prelimenrary implementation of the model indicated that the model predictions relatively agreed with the experimental results. After conducting a calibration procedure, lower error was obtained $20.45 \%$. However, by excluding the results at very low feed rates to duduct its erratic influence, the average error substantially reduced to $11.18 \%$ using cutting tools with nose radius of $200 \mu \mathrm{m}$.
\end{abstract}

\section{KEYWORDS}

Ultra-precision Turning, Surface Roughness, Minimum Chip Thickness, Elastic Recovery, Dual-phase Material, Process Uncertainty

Prod. Eng. \& Mech. Design Depart., Faculty of Eng., Port Said University, Port said, Egypt.

Lecturer of Production Eng., Faculty of Eng., Port Said University, Port said, Egypt.

Prof. of Production Eng., Faculty of Eng., Shoubra, Benha University, Benha, Egypt.

Prof. of Production Eng., Faculty of Eng., Ain Shams University, Cairo, Egypt.

Prof. of Production Engineering, Faculty of Eng., Port Said University, Port said, Egypt. 


\section{INTRODUCTION}

Recently there has been an enthusiastic demand for miniaturized components with complex micro features to fulfill industrial requirments in several fields such as medical, telecommunication, avionics, biotechnology, and electronics [1, 2]. Most of these products fall into the micro scale range (from $10 \mu \mathrm{m}$ to $1 \mathrm{~mm}$ ) [3]. The need for dependable micro-components for such applications is associated with stringent constraints on the micro-fabrication processes used, where mechanical micromachining is a preferable choice.

This is not surprising knowing that mechanical micro-machining has demonstrated high capabaility to produce products with superior quality in shorter time when compared with other manufacturing techniques [4]. Consequently, mechanical micro-machining has attaracted researchers and industrial interest. Especially, many researchers have dedicated their works to examine the micro-machining process aimig at identifying the optimum conditions for the maximum process outcomes [5].

Transition between macro and micro machining passing through precision and ultraprecision machining have attracted great attention from manufacturer and scientific communities over the past few years. It is obvious that precision and ultra-precision concern producing accurate and cost-effective products with ranges of dimensions starts from $10 \mathrm{~nm}$ to $1 \mathrm{~nm}$ for both techniques, respectively [6]. Precision and ultraprecision are widely used in the field of high technology in industrial applications such as lasers, optics, quartz vibrators, semi-conductors, aircraft and artificial satellites...etc [7-9].

Due to the restricted range scale in ultra-precision machining it's essential to evaluate the achievable surface of the final products, because it is very difficult to apply any subsequent corrective processing to improve the quality. Micro-machining and ultraprecision machining are kinematically similar to traditional/macro machining. However, a number of underlying differences have been emerged owing to the different ranges of scale at which each manufacturing technique takes place [10]. In particular, the challenge that researchers face in ultra-precision machining is the significant reduction of the applied cutting paramters and the tool edge radius, which normally varies from $2 \mu \mathrm{m}$ to $10 \mu \mathrm{m}$, and in turn becomes comparable in size-scale to the thickness of the material to be cut $[9,11]$. As a result, cutting takes place with a highly negative tool rake angle and consequently the ratio of the thickness of the material to be cut and the tool edge radius will determine the chip removal mechanism [12]. In paricualr, the chip will not form unless the cutting thickness is greater than a critical value so-called the minimum uncut chip thickness $\left(h_{m}\right)$ [13]. When the uncut chip thickness $(h)$ is very small where chip cannot be formed, the minimum chip thickness effect dominating the cutting regime and ploughing mechanism governs the material behavior as shown in Fig. (1) [1]. The minimum uncut chip thickness is considered a material property and depends on several factors such as the mechanical properties of the workpiece material and friction between cutting tool flank face and workpiece surface. The cutting at such scale is associated with the so-called size-effect phenomena, where the conventienal proportional relationship between the the uncut chip thickness and the energy consumed is no longer valied [14]. 
Although there have been considerable therotical and experimental investigations of the size-effect, predicting accurate value of the minimum chip thickness is not straightforward. However, it is reported that minimum chip thicknss normally falls in the range of $5 \%$ to $40 \%$ of the cutting tool edge radius [16]. In additions to the minimum chip thickness property, stochastic behaviour of the material microstructure also involves spring back of the uncut matrial which is considered another source of unpredictable performance of the process. It is also called elastic recovery and defined as the ratio between the actual penetration depth of the tool to the actual resultant depth [17].

Due to the fact that multi-phase material is a blend of different phases with exterminly different mechanical properties, it is not so difficult to expect varying values of the minimum chip thickness and elastic recovery for these phases within the microstructure. These alterations lead to different responses of the material to be cut based on the phase in contact with the cutting tool. Accordingly, the stochastic behavior of any processed microstruce, especially in case of multi-phase materials, has an uncertainty contribution to the surface generation process. Thus, such uncertain regime has to be assessed and considered for succssesful implementation of the process [18].

An early attempt to study the effect of minimum chip thickness on generated surface in micro-milling was made by Vogler et.al. [9], where a comparison of surface roughness with and without the effect of minimum chip thickness was developed. Particularly, without this effect, the surface roughness values would presented the conventional trend of increasing roughness with the increase in feed rate. However, when considering the minimum chip thickness effect on surface roughness, it dominated the process mechanism at lower values of the feed rate. As the feed rate increased, the surface roughness decreased to acertain value of feed rate then the trend reversed and increased with the increase in applied feed rate [9]. The authors concluded that the minimum chip thickness contributed to $40 \%$ of the achievable surface roughness at micro-scale.

From the undertaken review, it is not so difficult to see the significate influence of the uncertainty of both minimum chip thickness and elastic recovery on the generated surface in micro and/or ultra-precision turning operation. However, so far there has been no comprehensive study of this phenomenon to enable precise prediction of the obtainable roughness during ultra-precision turning.

Thus the motivation for this work was to address this inadequate understanding of the process perfomance. In this context, the aim of this research is to develop a model for predicting the surface roughness considering the effect of uncertainty of elastic recovery and minimum chip thickness when machining multi-phase materials at microscale.

The paper is organized as follows; the next section presents the development model for predicting surface generation in ultra-precision turning (single point tool). Next, the experimental trials used to validate the predictions of the proposed model is outlined. Then, a comparison betweenthe the model predictions and experimental results is reported and discussed. Finally, conclusions and perspective are drawn in the last section 


\section{SURFACE GENERATION MODELING APPROACH}

In the present work, surface generation modeling approach of ultra-precision turning is developed to predict the resultant surface roughness in ultra-precisin turning considers the kinematic parameters (feed rate, nose radius and cutting edge radius) in addition to the stochastic parameters, namely elastic recovery $(k)$ and minimum chip thickness (tcmin).

Owing to the fact that turning process is implemented using a single cutting edge tool with a pre-defined nose radius $\left(r_{c}\right)$, it is considered a significant geometry variable to dominate the surface profile. Consequently, the theoritical roughness $\left(R_{t h}\right)$ is a function of feed per revolution $(f)$ and nose radius $\left(r_{c}\right)$. The theoretical surface roughness $\left(R_{t h}\right)$ is defined as a periodic function $\mathrm{x}(\mathrm{z})$ which applied on the distance between two consecutive surfaces, which is also referred to the feed rate. However, considering the size scale at which the cutting takes place, where the applied feed becomes in the vicinity of the cutting edge radius of the tool, the underlying mechanism alters between cutting and ploughing, and thus surface generation process obviously differs from those at macro-scale machining. Fig. (2) shows the fundamental of the ultra-precision turning process, where the effects of the stochastic parameters on surface generation mechanism can be revealed. To implement the modeling procedure of the resultant surface at ultra-precision turning, the cartesian coordinates of $X$ and $Z$ axis were set to presents the points along the surface profile, where $X$ value is the height of each point of the surface profile and $Z$ value denotes the longitudinal movement of the tool in feed direction. To determine the generated profile, the model considers two adjacent tool profiles, the current tool profile and preceeding one. The newely generated surface is a combination of the tool geometry and the elastic recovery contribution, part in the uncut chip zone due to the minimum chip thickness effect.

The proposed model initiates by counting a determinsteic equation of tool profile in form of circular arc, which can be presented by Eq. (1):

$$
(X \text { cordinate of the point })^{2}+(Z \text { coordinate of the point })^{2}=(\text { nose radius })^{2}
$$

As the origin was set at the centre point of the previous profile, so, Eq. (1) is modified to evaluate to current profile measured from the origin, where the hight $X$ of the gererated surface in terms of tool nose radius as shown in Eq. (2), The range of $X$ is taken from $-\mathrm{f} / 2$ to $\mathrm{f} / 2$.

$$
\mathrm{X}^{2}+(\mathrm{Z}-\mathrm{f})^{2}=\mathrm{rc}^{2} \text { for }-\frac{f}{2} \leq z \leq \frac{f}{2}
$$

The represent the temporarily surface of the current profile. However, the profile of the previous surface is presented by the Eq. (3):

$$
X^{2}+(Z)^{2}=r_{c}^{2}
$$

The step distance between each two adjacent profiles equals the applied feed where the theoretical intersection point (Sthi-1) between the two neighboring profiles can be determined from the equations of two profiles, Eq. (2) and Eq. (3) that considere the value of the tool nose radius and feed rate, as shown in Fig. (3). Then, for each point 
along the current profile $\left(S_{t c i}\right)$, its distance $(L)$ from the center point of previous profile curve $\left(\mathrm{C}_{\mathrm{i}}\right)$ is detrimned as shown in Eq. (4)

$L=\sqrt{(f-z)^{2}+(x)^{2}}$

After that, by subtracting the magnitude of the nose radius $\left(r_{c}\right)$ from line $(L)$, the distance ( $/$ between each two corresponding points along the two consecutive profiles (Stci-1 and $S_{t c i}$ ) can be identified. To count for the effect of minimum chip thickness and elastic recovery, the distance $(I)$ is compared with the minimum chip thickness value, $t_{c m i n}$, for a given phase present within the material microstructure. The minimum chip thickness taken in this model is an average value of the minimum chip thickness for both phases of material microstructure $t_{c m i n}$, $t_{c m i n}[1,16]$. The minmum chip thickness and elastic recovery of Brass 6040 have range values of $(0.46: 0.57)$ and $(0.57: 0.88)$, respectively [15].

Next, this leads to three possible cases:

1 ${ }^{\text {st }}$ Case: If $\left(S_{t c i-1}, S_{t c i}\right)<t_{c e}$ where $\left(t_{c e}\right)$ is minimum chip load at below which no plastic deformation takes place and only elastic behavior of the material occurs. In this case the processed material is fully elastic recovered and the generated surface is presented by the point of the previous profile $\left(\mathrm{S}_{\mathrm{tci}-1}\right)$.

$2^{\text {nd }}$ Case: If $t_{c e}<\left(S_{t c i-1}, S_{t c i}\right)<t_{c m i n}$

In this case, the underlying mechanism is plastic deformation where ploughing is the dominate regime. In particular, no cutting and only plastic deformation with partial elastic recoverly obtained according to the elastic recovery rate of the material (k).

$3^{\text {rd }}$ Case: If $\left(\mathrm{S}_{\mathrm{tci}-1}, \mathrm{~S}_{\mathrm{tci}}\right)>\mathrm{t}_{\mathrm{cmin}}$

In this case cutting is the prevailing mechanism, with no ploughing rather elastic recover, where the minimum chip thickness has no effect. Then, the resultant profile at this point is represented by the points $\left(\mathrm{S}_{\mathrm{tci}}\right)$.

Finally, the entire surface generation in ultra-precision turning is modeled that involves a blend of the theroretical paramters, as in case three, and the stochastic variables associated with uncertainty due to the influence of the minimum chip thickness and elastic recovery of phases present within material microstructure.

\section{EXPERIMENTAL VALIDATION}

A CNC center-lathe machine, BINNS\&BERRY, was used to carry out longitudinal turning passes using single carbide insert tool (TCGT16T302) by KORLOY Inc. The cutters used in this study had the following geometric parameters, cutting nose radius $\left(r_{c}\right)$ was $200 \mu \mathrm{m}$, and the cutting edge radii $\left(r_{e}\right)$ in the range of $5 \mu \mathrm{m}$. Fig. (4) shows the machining setup of Brass 6040. 


\section{Cutting Conditions}

The cutting parameters applied during the experiments are presented in Table 1. In order to reveal the effects of the minimum chip thickness and associated elastic recovery on the cutting mechanism, especially the alterations between cutting and ploughing, the experiments covered a wide range of feeds from 5 to $70 \mu \mathrm{m} /$ revolution with constant increment of $5 \mu \mathrm{m}$. Owing to the limited influence of the other two machining parameters on the process performance and due to the fact that the proposed model does not consider them, they were kept constant. In particular, the maximum available spindle speed of $1000 \mathrm{rpm}$ was selected which was equivalent to $150 \mathrm{~m} / \mathrm{min}$ and also one level of axial depth of cut, $50 \mu \mathrm{m}$, was applied to limit the workpiece /cutter engagement in the nose of the tool.

\section{Workpiece Microstructure}

To validate the proposed model, an experimental study was conducted on dual-phase sample, Brass 6040, and thus to compare the modeling predictions with the experimental results. In order to judge the smaple's microstructure, Brass 6040 sample was polished and etiched using $30 \mathrm{ml} \mathrm{HCl}, 10 \mathrm{gm} \mathrm{Fe} \mathrm{Cl} 3$ and $120 \mathrm{ml}$ ethanol. Fig. (5) show the microstructure of Brass 6040 sample.

In Fig. (5) of the Brass 6040 microstructure, the $\alpha$-phase is the bright material and the $\beta$-phase is the dark one that called the second Hume-Rothery phase. In order to get the mechanical properties of a material microstructure, the micro- hardness test indicates that the average hardenss of $\alpha$-phase and the second Hume-Rothery phase were approximately $125 \mathrm{HV}$ and $203 \mathrm{HV}$, respectively [19]. However, with such blended microstructure, in Brass 6040, it is expected that the surface generation process will be significantly affected by the stochastic performance of the microstructure due to the different machining response of each phase within the microstructure.

\section{Measurement Uncertainty}

The measurement of surface roughness were undertaken manually, and thus there was some uncertainty in performing such measurements. To overcome the consequence of this uncertainity, measurements were taken after relatively considerable increments in machining length, and hence removed volumes, in order to judge clearly about the increases of surface roughness. However, to validate the measured value of surface roughness obtained for a given cutting condition, measurement uncertainty has to be studied. All measuremants were taken with the same surface roughness instrument and it was assumed that the source of uncertainty in inspecting the roughness were the same for all measurements [20]. The standered uncertainty, $u$, explained by Eq. (6)

$$
u=\frac{s}{\sqrt{n}}
$$

where $(s)$ is the evaluated standered deviation and $(n)$ is the number of measurements in the set. To perform this measurements, seven measurements were conducted for 
each of specimen with three diferent roughness measurments, the lowest and the highest values with one in the middle for each materials.

\section{RESULTS AND DISCUSSION}

\section{Uncertainity Analysis}

Particularly, the uncertainty measurement of roughness is applied on the machined specimen of Brass 6040 using cutting tool with nose radius $200 \mu \mathrm{m}$. The minimum, medium and maximum roughness values of $0.77 \mu \mathrm{m}, 0.98 \mu \mathrm{m}$, and $2.03 \mu \mathrm{m}$, respectively are presented. The estimated standerd deviation, $\mathrm{s}$, was calculated to be $0.166 \mu \mathrm{m}, 0.035 \mu \mathrm{m}$, and $0.045 \mu \mathrm{m}$, respectively, while the stander measurements uncertainty were $0.063 \mu \mathrm{m}, 0.013 \mu \mathrm{m}$, and $0.017 \mu \mathrm{m}$, respectively.

The measurement uncertainty of Brass 6040 was found highly dependent on the range of surface roughness to be measured. In particular, the uncertainty measurement using cutting tool with nose radius $200 \mu \mathrm{m}$ decreased with the increase of the measured value of surface roughness. Thus, seven readings were taken for each measurement to minimize the measurement uncertainty.

\section{Surface Roughness}

The roughness of the machined surface was examined using Taylor and Hobson Surtronic 3 Profilometer with $4.8 \mathrm{~mm}$ standard tracing length and $0.8 \mathrm{~mm}$ cutoff distance. For each specmen, the surface roughness results were obtaind by evaluating the average of seven measurements at differnet positions along the cercumference of the machined part.

Fig. (6) shows the resultant surface roughness for Brass 6040 over the considered feed range and tools with nose radius of $200 \mu \mathrm{m}$, where $5 \mu \mathrm{m}$ of cutting edge radius of the tools were used. The experimental results revealed that the highest value of surface roughness was obtained at very low feed where the minimum chip thickness and elastic recovery dominated the cutting regime. This shows the significant effect of the minimum chip thickness, especially when the values of applied feed is comparable to the cutting edge of the tool. However, the values of surface roughness gradually decreased with the increase of the applied feed up to a feed value of $10 \mu \mathrm{m} /$ revolution where the minimum roughness was achieved. The optimum roughness was achieved at feed value was double the cutting edge radius of the tool. With the increase of feed beyond the optimum point, the roughness increased again due to the effect of the kinematic paramters similar to those at conventional machining [9].

Before comparing the experimental results with the modling predictions, theoretical roughness $\left(R_{\mathrm{t}}\right)$ was detrmined that considers the kinematic paramters only as presented in Eq. (7) [21];

$$
R_{t}=\frac{0.032 f^{2}}{r_{c}}
$$

where, $f$ is the feed ( $\mu \mathrm{m} /$ revolution), and $r_{c}$ is the nose radius $(\mu \mathrm{m})$ 
As shown in Fig. (6), it is not so difficult to see the large discripancies between the experimental results and prediction of the theoretical roughness.

Then the proposed model was implemented using MATLAB software package, where the simulation trials were undertaken at the same cutting parameters and tool geometry as those applied in the experimental study.

From the literature, it was found that the minimum chip thickness and elastic recovery of $\alpha$-phase are $0.57^{\star} r_{e}$ and 0.57 , while they are $0.46^{*} r_{e}$ and 0.88 for $\beta$-phase, respectively. To implement the simulation runs, the average of the minimum chip thickness and elastic recovey of the two phases were utilized for the initial results. Although, better matches where detected than the results of the theoretical roughness, high average error was obtained, which is attributed to the uncertainty errors due to the blend nature of the microstructure. So, to count for the effect these errors, uncertainty values (percentage of the average value) of the minimum chip thickness and elastic recovery value were added gradualy. Although, good agreement between the experimental results of surface roughness and those obtained from the molding approach, particularly at high feeds, this is not the case at low feeds. Thus calibration process was performed to improve the results to match the experimental results better. In paricualr, the obvious matching between deterministic surface roughness and experimental results can be explained by the decreases of stochastic surface roughness components and ploughing at high feeds. According to the significant of stochastic surface roughness components, the calibration process needed, because of the difficulty of obtaining the stochastic surface roughness components directly from experimental measurement. So, the stochastic surface roughness components have to be determined by subtracting the deterministic ones from the total measured surface roughness.

For the error calculations, in case of machining Brass 6040 using cutting tool with nose radius $200 \mu \mathrm{m}$ as shown in Fig. (6); the average error between experimental results and kinematic roughness was $71.42 \%$. After simulation with the average values of the minimum chip thickness and elastic recovery, particularly at value of $0.515^{\star} r_{e}$ and 0.725 , respectively, the average error reduced to $47.8 \%$. However, the average error between simulation and experimental results reduced to $35.5 \%$ when the average values of the elastic recovery and minimum chip thickness increased by $10 \%$ and $20 \%$, respectively. After calibration, the simulated results showed a good agreement with the experimental ones with an average error of $20.45 \%$.

\section{CONCLUSION}

This paper has presented a modeling approach of predicting the surface generation process during ultra-precision turning of multi-phase materials together with an experimental study to validate it. The developed model of the ultra-precision turning process was utilized to simulate the surface generation process associated with the machining of multi-phase materials. It considered the effects of the kinematic factors, feed rate, and the cutting tool geometry in addition to the material characteristics in term of minimum chip thickness and elastic recovery. The model paid great deal of attention to the contribution of uncertainty due to the effect of elastic recovery and the minimum chip thickness on surface roughness generation. 
An experimental study was conducted on Brass 6040 alloy to validate the proposed model. In particular, longitudinal turning test was performed on Brass 6040 sample under feed rates ranging from 5 to $70 \mu \mathrm{m} /$ revolution with constant speed and depth of cut using cutting tool with two different nose radius of $200 \mu \mathrm{m}$.

Subsequently, the roughness of the generated surfaces were measured and compared with the predictions of the developed model under the same cutting conditions. The following specific conclusions were drawn;

- The study showed a good agreement between the experimental and simulation results after calibration to remove the stochastic component. The average error for brass 6040 was found $20.45 \%$ when machining with cutting tool with nose radius of $200 \mu \mathrm{m}$.

- The model had good agreement with experimental results after excluding the zone of low feed rates at which the minimum chip thickness effect dominated the underlying mechanism. In particular, the average error for brass 6040 reduced to $11.18 \%$ when machining with cutting tool with nose radius of 200 $\mu \mathrm{m}$.

- Finaly,the results of this research showed clearly that a special attention should be paid to the effect of uncertainty of elastic recovery and minimum chip thickness on surface generation.

\section{ACKNOWLEDGMENT}

The authors wish to thank the Suez Canal Authority for providing technical support to the authors to fulfill this research endeavor. Also, the authors gratefully acknowledge the support of Eng. Ali Abdel aziz from the Suez Canal Authority workshop for his support in conducting the machining trials.

\section{REFERENCES}

[1] X. Liu, R.E. Devor, and S.G. Kapoor, "Model-based analysis of the surface generation in microendmilling-Part I: Model development” ,ASME J. Manuf. Sci. Eng., 129, pp. 453-460 (2007).

[2] W. Jihua and L. Zhanqiang, "Modeling of flow stress in orthogonal microcutting process based on strain gradient plasticity theory" ,Int.J. Adv. Manuf. Technol., 46, pp.143-149 (2010).

[3] X.M. Lai, H.T. Li and C.F. Li, "Modelling and analysis of micro scale milling considering size effect, micro cutter edge radius and minimum chip thickness", Int. J Mach Tools Manuf., 48, pp. 1-14 (2008).

[4] X.M. Lai, H.T. Li and C.F. Li," Modelling and experimental analysis of the effects of tool wear, minimum chip thickness and micro tool geometry on the surface roughness in micro-end-milling", J. Micromech. Microeng.,18, pp. 025006 (12) (2008).

[5] R. Venkata Rao and V.D. Kalyankar," Optimization of modern machining processes using advanced optimization techniques: a review", International Journal of Advanced Manufacturing Technology, vol. 73, pp:1159-1188 (2014). 
[6] D. Dornfeld, S. Min and Y. Takeuchi, "Recent Advances in Mechanical Micromachining", CIRP Annals, vol 55, 2, pp: 745-768 (2006).

[7] A. Pramanik, K. S. Neo, M. Rahman, X. P. Li. M. Sawa and Y. Maeda, " Ultra precision turning of electroless nickel: effects of crystal orientation and origin of diamond tools", Int.J. Adv. Manuf. Technol., 43, pp. 681-689 (2009).

[8] K. Jeong-Du and K. Dong-Sik, "Development and Application of an Ultraprecision Lathe", Int J AdvManufTechnol, 13, pp. 164-171(1997).

[9] M. Vogler, S. Kapoor and R. Devor,"On the modeling and analysis of machining performance in microendmiling, Part 1: Surface generation", ASME J. of Manufacturing Science and Engineering, 126, pp. 685-694 (2004).

[10] P. Piljek, Z. Keran and M. Math "Micromachining - review of literature from 1980 to 2010",Interdisciplinary Description of Complex Systems, Vol. 12(1), pp: 1-27 (2014).

[11] K. Liu, "Process modelling of micro-cutting including strain gradient effect", PhD Thesis, George W. Woodruff School of Mechanical Engineering Georgia, Institute of Technology, USA (2005).

[12] A. J. MIAN " Size Effect in Micromachining," PhD thesis, Faculty of Engineering and Physical Sciences, The Univ. of Manchester, UK (2011).

[13] F. B. Oliveira, A. R. Rodrigues, R. T. Coelho, and A. F. Souza, "Size effect and minimum chip thickness in micromilling", International Journal of Machine Tools \& Manufacture, 89, pp.39-54 (2015).

[14] T. Zhang, Z.Liu, Z. Shi and Ch. Xu "Size Effect on Surface Roughness in Micro Turning", International Journal of Precision Engineering and Manufacturing, 14 (3), pp. 345-349 (2013).

[15] J. Chae, S.S. Park and T. Freiheit, "Investigation of Micro-cutting operations", Int. Journal of Machine Tools and Manufacture, 46 (3-4), pp. 313-332 (2006).

[16] X. Liu,R. E. DeVor and S. G. Kapoor "An Analytical Model for the Prediction of Minimum Chip Thickness in Micromachining," ASME for publication in the Journal of manufacturing science and engineering, Vol. 128, pp: 474481(2006)

[17] A.M.A. Elkaseer, and E.B. Brousseau,"Modelling the surface generation process during AFM probe-based machining: simulation and experimental validation", Surf. Topogr.:Metrol. Prop., 2,025001 (12pp) (2014).

[18] A.M.A. Elkaseer, S.S. Dimov, K.B. Popov, M. Negm and R. Minev," Modeling the Material Microstructure Effects on the Surface Generation Process in Microendmilling of Dual-Phase Materials", journal of Manufacturing Science and Engineering, 134, pp. 044501(1-10) (2012).

[19] A.M.A. Elkaseer, and E.B. Brousseau,"AFM probe-based mechanical machining: Modelling of the surface generation process," 7th International Conference on Micro Manufacturing (ICOMM2012), pp. 78-84 (2012).

[20] A.M.A. Elkaseer, S.S. Dimov, K.B. Popov and R. Minev, " Tool Wear in Micro-Endmilling: Material Microstructure Effects, Modeling, and Experimental Validation," Journal of Micro and Nano-Manufacturing, vol 2(4):044502 (2014).

[21] Z. Jurkovic, G. Cukor and I. Andrejcak "Improving the surface roughness at longitudinal turning using the different optimization methods", Technical Gazette, Vol. (17), pp: 397-402 (2010). 


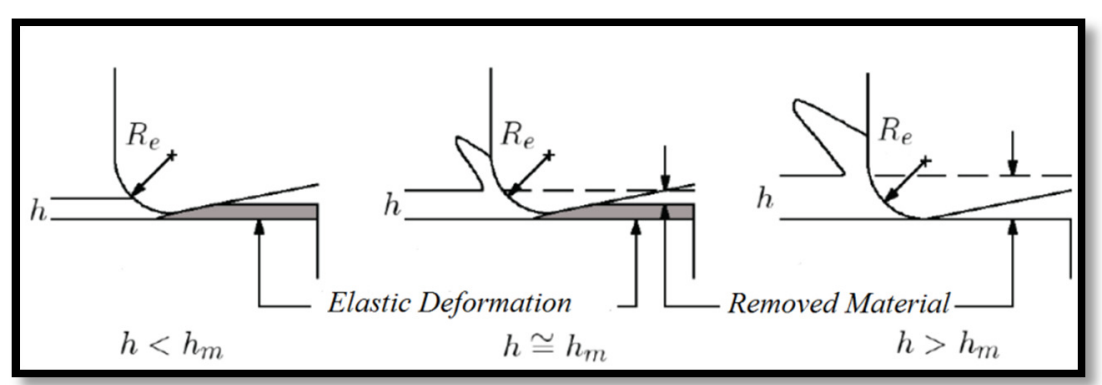

Fig. (1): Schematic representation of the minimum chip thickness in orthogonal cutting [15].

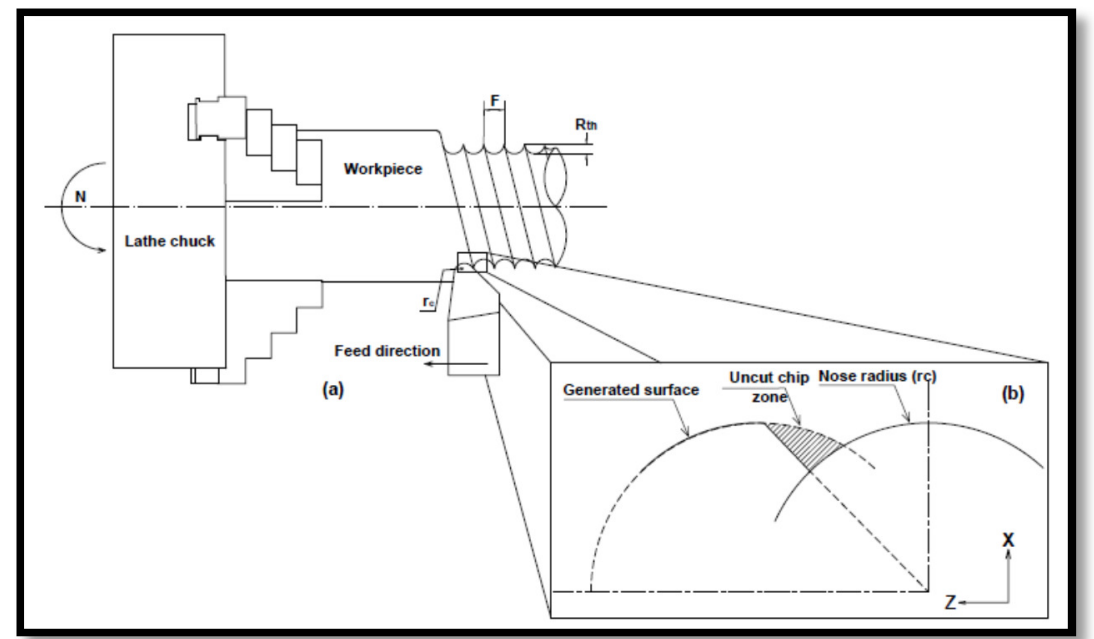

Fig. (2): Generated surface in ultra-precision turning operation.

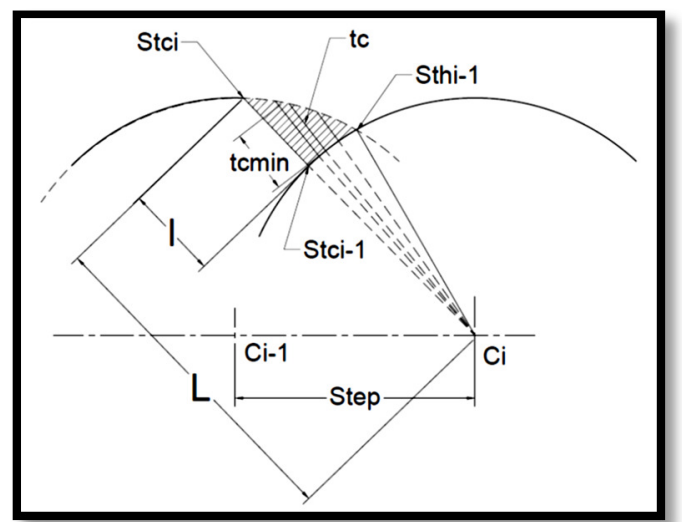

Fig. (3): Surface generation in the feed direction during ultra-precision turning. 


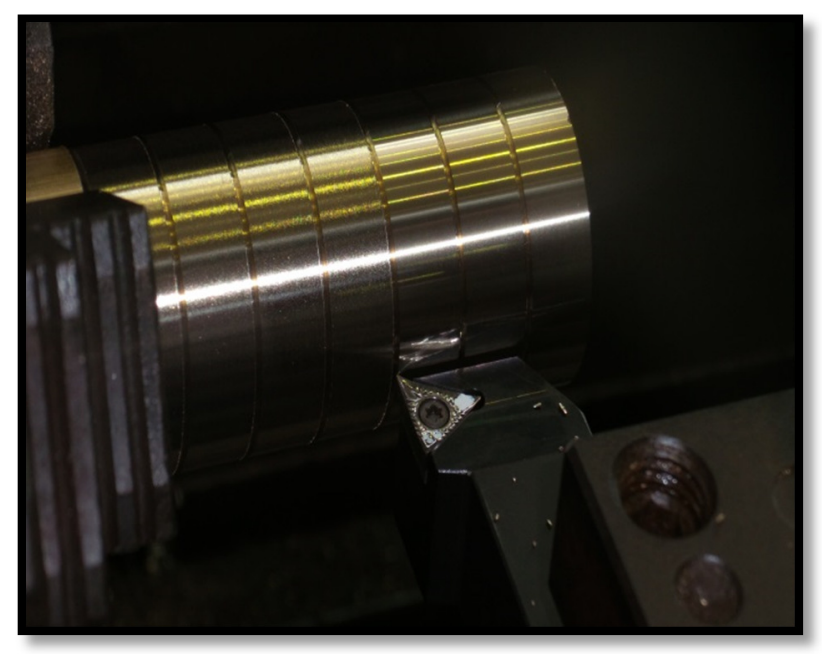

Fig. (4): The machining setup for Brass 6040.

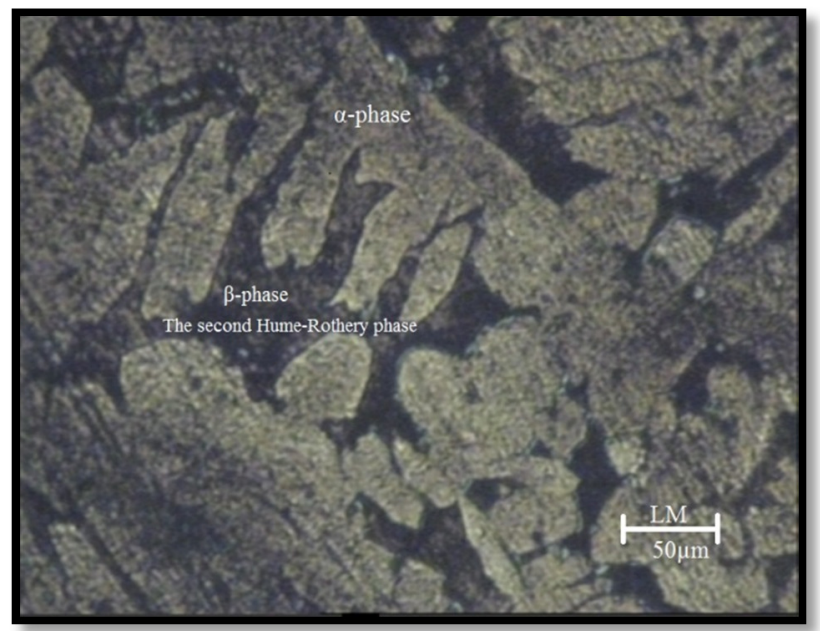

Fig. (5): Light Micrographs (LM) of Brass 6040.

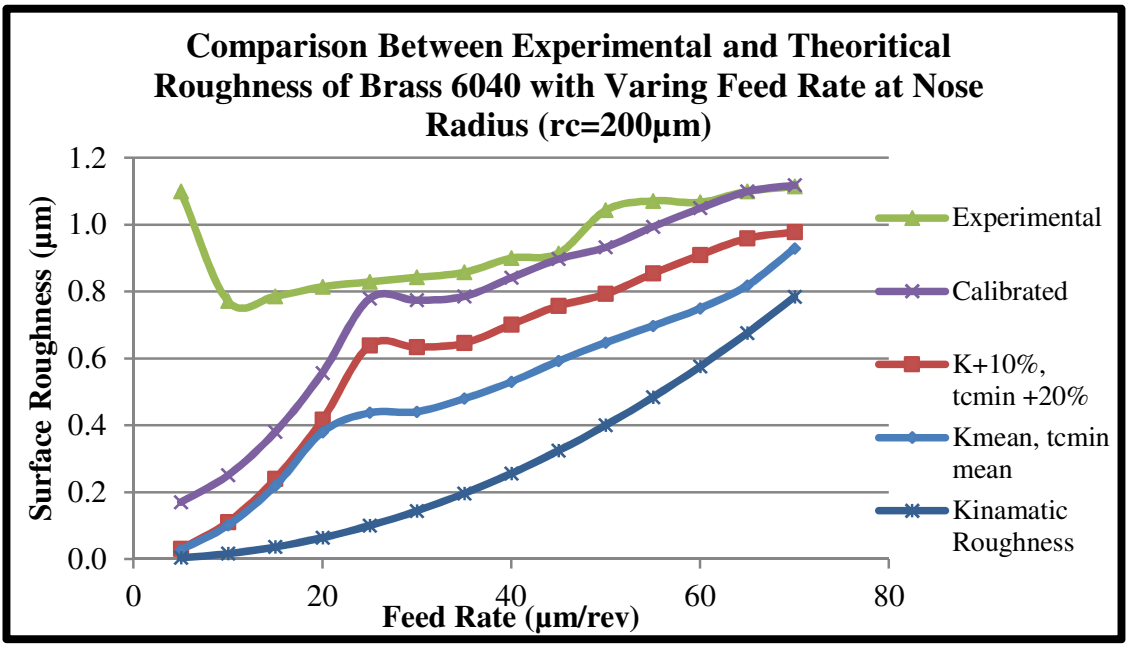

Fig. (6): Comparison between experimental and simulation surface roughness results of brass 6040 at nose radius of $200 \mu \mathrm{m}$. 
Table 1: Cutting conditions.

\begin{tabular}{ll}
\hline \hline Depth of cut $(\mu \mathrm{m})$ & 50 \\
Cutting speed $(\mathrm{m} / \mathrm{min})$ & 145 \\
Feed $(\mu \mathrm{m} /$ revolution $)$ & $5-10-15-20-25-30-35-40-45-50-55-60-65-$ \\
& 70 \\
\hline \hline
\end{tabular}

